\title{
Biological Characterization of Clones Derived from the Edmonston Strain of Measles Virus in Comparison with Schwarz and CAM-70 Vaccine Strains
}

\author{
Maria Beatriz Junqueira Borges ${ }^{+}$, George $F$ Mann, Marcos da Silva Freire
}

Bio-Manguinhos, Fundação Oswaldo Cruz, Av. Brasil 4365, 21045-900 Rio de Janeiro, RJ, Brasil

Four virus clones were derived from the Edmonston strain of measles virus by repeated plaque purification. These clones were compared with the vaccine strains Schwarz and CAM-70 in terms of biological activities including plaque formation, hemagglutination, hemolysis and replication in Vero cells and chick embryo fibroblasts (CEF).

Two clones of intermediate plaque yielded mixed plaque populations on subcultivation whereas the other two, showing small and large plaque sizes, showed stable plaque phenotypes. The vaccine strains showed consistent homogeneous plaque populations.

All the Edmonston clones showed agglutination of monkey erythrocytes in isotonic solution while both vaccine strains hemagglutinated only in the presence of high salt concentrations.

Variation in the hemolytic activity was observed among the four clones but no hemolytic activity was detected for the vaccine virus strains.

Vaccine strains replicated efficiently both in Vero cells and CEF. All four clones showed efficient replication in Vero cells but different replication profiles in CEF. Two of them replicated efficiently, one was of intermediate efficiency and the other showed no replication in CEF.

Two of the clones showed characteristics similar to vaccine strains. One in terms of size and homogeneity of plaques, the other for a low hemolytic activity and both for the efficiency of propagation in $C E F$.

Key words: biological characterization - plaque variants - measles - vaccine

Measles is a viral exanthematic disease, considered as one of the most contagious infections of mankind, which still causes the death of over one million children per year, mainly in the developing world. The severity of measles is due to the immune suppression caused by the virus leading to secondary infections and also for the role in the establishment of a slow progressive disease of the nervous system, subacute sclerosing panencephalitis (SSPE). After the successful introduction of the vaccine in 1964 together with the fact that measles virus is considered monotypic and has no animal reservoir, measles was considered as potentially eradicable. Current licensed vaccines are safe and effective. They are, however, limited by the requirement for constant refrigeration and by interference of transplacentally acquired maternal antibodies (Gellin \& Katz 1994). Variation exists between virus strains in monoclonal antibody reactivity (Hu et al. 1993), plaque formation (Rapp 1964, De Maeyer \& Enders 1965), temperature sensitivity (Haspel et al. 1975), ability to induce

${ }^{+}$Corresponding author. Fax: 55-21-260.4727

Received 27 October 1995

Accepted 9 April 1996 interferon (McKimm \& Rapp 1977), hemagglutination (Schluederberg \& Nakamura 1967), as well as in nucleotide sequence (Rota et al. 1994). However, the biological significance of this variation and the correlation with virulence and attenuation need to be established in order to evaluate the efficacy of eradication programmes. The envelope of measles virus carries two transmembrane glycoproteins which are biologically important antigens for representing the primary targets in immune response. The hemagglutinin $(\mathrm{H})$ is responsible for host cell recognition through receptor binding and agglutination of red blood cells. The fusion (F) protein is involved in fusion of the viral and cell membranes, viral penetration and hemolysis (Bellini et al. 1994). In this study we compare biological activities of different strains of measles virus such as plaque formation, hemagglutination, hemolysis and replication in Vero cells and in chick embryo fibroblasts (CEF).

\section{MATERIALS AND METHODS}

Virus strains - The cell culture adapted Edmonston strain was provided by CDC, Atlanta, (Hummel et al. 1992) and passaged five times in Vero cells. This strain yielded a mixed plaque population from which were derived four clones 
by plaque purifications. The Schwarz vaccine strain was obtained from the Rouvax (Pasteur Mérieux) commercial vaccine. The vaccine strain CAM-70 was obtained from the commercial vaccine from Bio-Manguinhos. All the strains studied were passaged twice in Vero cells to prepare the seed lot.

Cells - Vero cells (Rhim et al. 1969) were obtained from the American Type Culture Collection and primary chick embryo fibroblasts (Rubin 1973) were cultured in 199 Earle's medium containing $5 \%$ foetal bovine serum and $40 \mu \mathrm{g} / \mathrm{ml}$ gentamycin. Monolayers of Vero cells for plaque assays were prepared at a density of $2.6 \times 10^{5}$ cells $/ \mathrm{cm}^{2}$ for an area of $9.6 \mathrm{~cm}^{2}$; monolayers of Vero cells for $25 \mathrm{~cm}^{2}$ flasks were prepared in a density of $1.2 \times 10^{4}$ cells/ $\mathrm{cm}^{2}$. Monolayers of CEF for $25 \mathrm{~cm}^{2}$ flasks were prepared in a density of $6 \times 10^{3}$ cells $/ \mathrm{cm}^{2}$. The cultures were kept in an incubator with $5 \% \mathrm{CO}_{2}$ in air, at $37^{\circ} \mathrm{C}$.

Plaque selection and plaque assays - Plaque assays were performed according to general method of Dulbecco and Vogt (1954). The viruses were inoculated in a volume of $0.3 \mathrm{ml} / 9.6 \mathrm{~cm}^{2}$ in 6-well plates and allowed to adsorb for $1 \mathrm{hr}$. The inoculae were then removed and replaced with $3 \mathrm{ml}$ of medium containing $0.6 \%$ agarose. After seven days of incubation at $37^{\circ} \mathrm{C}$ the cells were stained by the addition of neutral red in medium to a final concentration of 1:20,000. Plaques were counted and measured at a magnification of $12.5 \mathrm{x}$. For plaque selection the dye was removed and a plug of agarose and cells was aspirated with a pasteur pipette from selected well separated plaques and inoculated into tubes with $1 \mathrm{ml}$ of medium containing $2 \times 10^{5}$ Vero cells. The cultures showing cytopathic effect were frozen and the cloning procedure repeated three to five times.

Hemagglutination - The hemagglutination tests were performed in round bottomed microtitre plates (Allison 1985). Twofold dilutions of the virus samples were prepared starting from 1:6, 1:7 and $1: 8$ using as diluent both PBS and $1.6 \mathrm{M}$ $\left(\mathrm{NH}_{4}\right)_{2} \mathrm{SO}_{4}$ in PBS (Shirodaria et al. 1976). An equal volume of rhesus monkey red blood cells $1 \%$ in PBS was added. Titres were determined after incubation at $37^{\circ} \mathrm{C}$ for $2 \mathrm{hr}$ as $\log _{10}$ of the reciprocal of the highest dilution which produced $50 \%$ agglutination. The amount of infectious virus required to hemagglutinate red cells was calculated from plaque assay results as $\log _{10} \mathrm{pfu} /$ HAU.

Hemolysis - Since hemagglutination is a prerequisite for hemolysis, hemolysis tests were initiated as described above (Allison 1985). The plates were then vigourously shaken and reincubated at $37^{\circ} \mathrm{C}$ overnight. Controls representing $100 \%$ hemolysis were prepared by mixing equal volumes of $0.1 \%$ Triton-X-100 with controls of non-agglu- tinated red blood cells. One hundred $\mu \mathrm{l}$ of PBS were added to all the wells and the plates centrifuged at $1000 \mathrm{x} g$ for $10 \mathrm{~min}$. The supernatants were transferred to flat bottomed plates in a volume of $100 \mu 1$. Optical densities (OD) were measured on a microplate reader at $405 \mathrm{~nm}$. The mean absorbance value produced by the $100 \%$ hemolysis controls and by the control RBC's was calculated. The background OD value represented by the control RBC's was subtracted from the OD values for the virus samples and the $100 \%$ hemolysis controls. The results were calculated as the $\log _{10}$ of the dilution which gave $50 \%$ hemolysis, relative to the controls. The amount of infectious virus required to produce $50 \%$ hemolysis of red cells was determined from plaque assay results as $\log _{10} \mathrm{pfu} / \mathrm{HLU}$.

Propagation in Vero cells and CEF - The efficiency of replication of the virus strains was evaluated by inoculating five cultures of each cell type with $1 \mathrm{ml}$ containing $10^{6} \mathrm{pfu}$ of each virus sample, at a MOI of 2.8 for CEF and 1.4 for Vero cells. The viruses were allowed to adsorb for $1 \mathrm{hr}$ at $37^{\circ} \mathrm{C}$. The inoculae were then removed, replaced by $10 \mathrm{ml}$ of fresh medium and the cultures reincubated at $37^{\circ} \mathrm{C}$. The culture flasks of each virus were frozen at $-70^{\circ} \mathrm{C}$ on days $0,2,4,6$ and 8 post-infection (p.i.) for Vero cells and days $0,2,4,7$ and 9 p.i. for CEF. After a single freeze/thaw cycle, virus samples were clarified at 2000x $g$ for $10 \mathrm{~min}$, and titrated by plaque assay.

\section{RESULTS}

The plaque phenotype produced by all the strains was observed after incubation of seven days at $37^{\circ} \mathrm{C}$. The Schwarz virus produced small plaques of $0.5 \mathrm{~mm}$ in diameter. The plaques produced by the CAM-70 strain were of intermediate size, with $2.5 \mathrm{~mm}$. The starting Edmonston virus contained a heterogeneous plaque population from which were derived four clones. Clone 1 was obtained after four plaque purifications and showed consistently mixed progeny of intermediate $(2.5 \mathrm{~mm})$ and small $(0.5 \mathrm{~mm})$ plaques. Clone 2 was also obtained after four plaque purifications and showed a stable population of small plaques $(0.5 \mathrm{~mm})$ which were indistinguishable from those of the Schwarz strain. Clone 3 was obtained after five plaque purifications and, as with clone 1 , showed a mixed progeny of intermediate and small plaques. For clones 1 and 3 the intermediate CAM70 like plaque predominated. The plaque population produced by clone 4 was of stable, large plaques, with $7.5 \mathrm{~mm}$ in diameter (Fig. 1). Both vaccine strains gave consistently homogeneous plaque populations (Table I).

Both of the vaccine strains hemagglutinated only in hypertonic saline while the four Edmonston clones hemagglutinated both in hypertonic and isotonic conditions (Table II). 

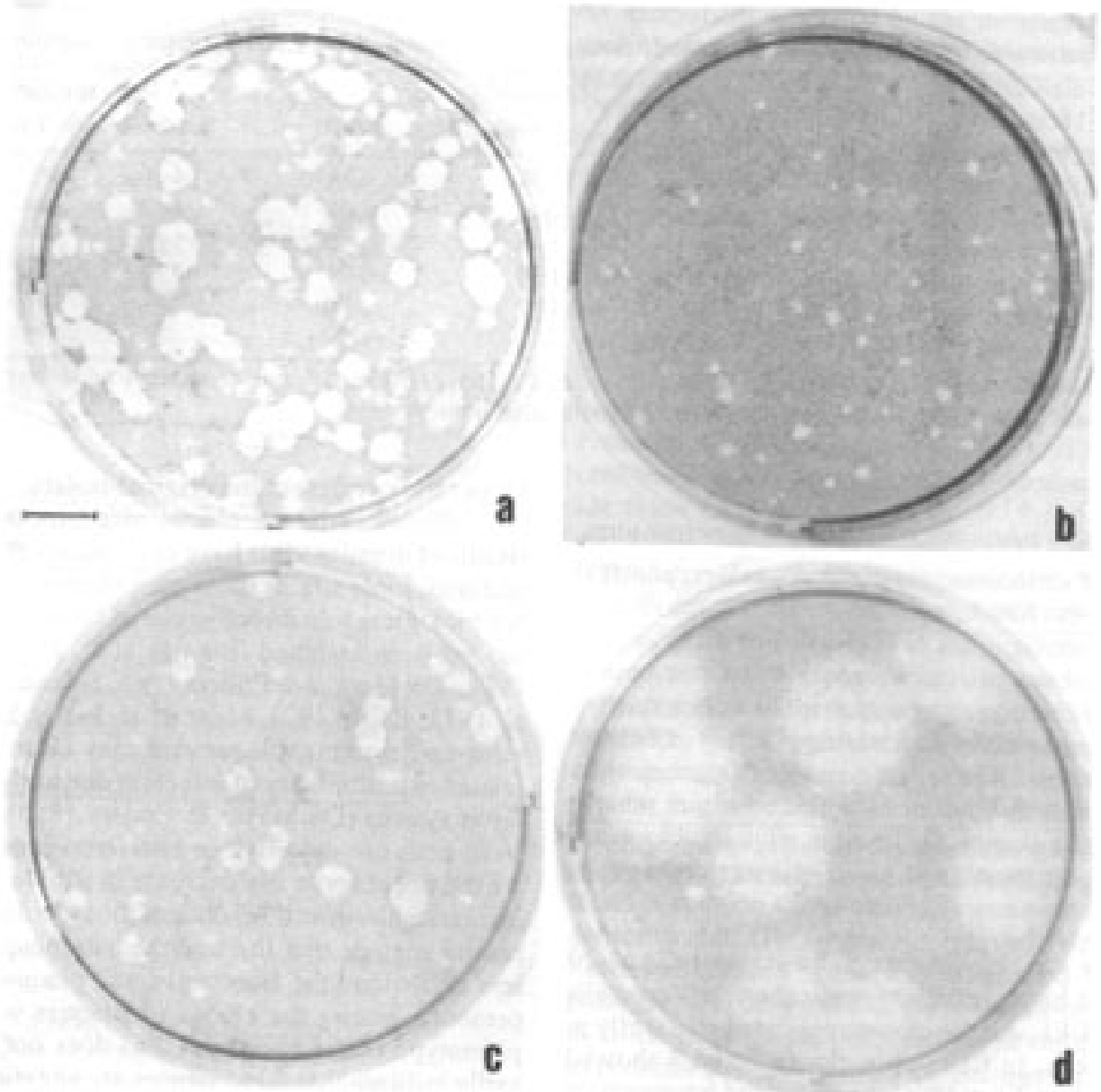

Fig. 1: plaques produced by clones derived from the Edmonston strain in Vero cells under agarose overlay, stained with neutral red. a: clone 1, b: clone 2, c: clone 3, d: clone 4 (Bar: $0.5 \mathrm{~cm})$.

\section{TABLE I}

Plaque type produced in Vero cells infected with measles virus under agarose overlay

\begin{tabular}{lccc}
\hline Virus & Plaque type & Diameter $(\mathrm{mm})$ & Progeny \\
\hline clone 1 & intermediate & 2.5 & mixed \\
clone 2 & small & 0.5 & stable \\
clone 3 & intermediate & 2.5 & mixed \\
clone 4 & large & 7.5 & stable \\
Schwarz & small & 0.5 & homogeneous \\
CAM-70 & intermediate & 2.5 & homogeneous \\
\hline
\end{tabular}

The vaccine strains Schwarz and CAM-70 did not produce hemolysis, even under hypertonic conditions. The relationship between infectious and hemolytic titres is shown in Table III. The results of the hemolysis assays for the four clones are shown in Fig. 2.

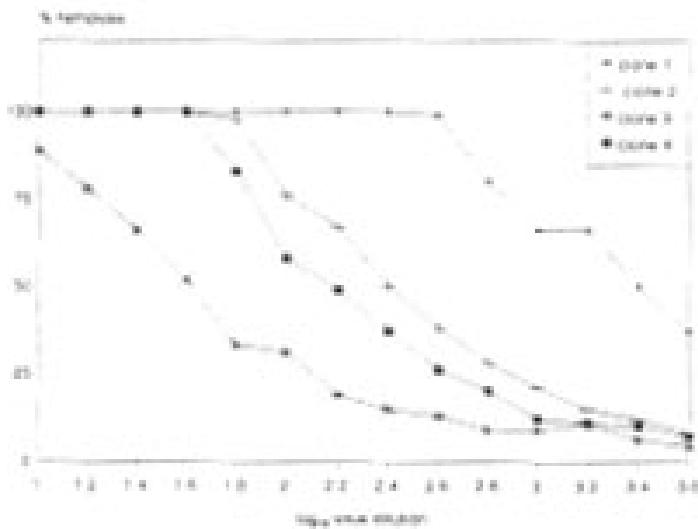

Fig. 2: relationship between dilution of the virus $\left(\log _{10}\right)$ and percentage of hemolysis induced in a red blood cell suspension. 
TABLE II

Relationship between infectious titres and hemagglutination under isotonic and hypertonic conditions

\begin{tabular}{|c|c|c|c|c|c|c|}
\hline \multirow[t]{2}{*}{ Virus } & \multirow{2}{*}{$\begin{array}{l}\text { Infectious } \\
\text { titres }^{a}\end{array}$} & \multicolumn{3}{|c|}{ HA titres ${ }^{b}$} & \multicolumn{2}{|c|}{$\log _{10} \mathrm{pfu} / \mathrm{HAU}$} \\
\hline & & isotonic & hypertonic & ratio* & isotonic & hypertonic \\
\hline clone 1 & 9.30 & 5.01 & 5.39 & 0.38 & 4.29 & 3.91 \\
\hline clone 2 & 8.34 & 3.76 & 4.79 & 1.03 & 4.58 & 3.55 \\
\hline clone 3 & 9.22 & 3.58 & 3.95 & 0.37 & 5.64 & 5.27 \\
\hline clone 4 & 9.20 & 3.58 & 4.49 & 0.91 & 5.62 & 4.71 \\
\hline Schwarz & 8.43 & $<1.60$ & 3.81 & $>2.20$ & - & 4.62 \\
\hline CAM-70 & 8.90 & $<1.60$ & 3.50 & $>1.90$ & - & 5.40 \\
\hline
\end{tabular}

$a$ : values expressed as $\log _{10} \mathrm{pfu} / \mathrm{ml} ; \quad b:$ values expressed as $\log _{10} \mathrm{HAU} / \mathrm{ml}$; *: rate of increase under hypertonic conditions; HA - hemagglutination; HAU - hemagglutination units.

TABLE III

Relationship between infectious and hemolytic titres

\begin{tabular}{lccc}
\hline Virus & $\begin{array}{c}\text { Infectious } \\
\text { titres }^{a}\end{array}$ & HL titres $^{b}$ & $\log _{10}$ pfu/HLU \\
\hline clone 1 & 9.30 & 4.72 & 4.58 \\
clone 2 & 8.34 & 3.71 & 4.63 \\
clone 3 & 9.22 & 3.21 & 6.01 \\
clone 4 & 9.20 & 3.46 & 5.74 \\
Schwarz & 8.43 & - & - \\
CAM-70 & 8.90 & - & - \\
\hline
\end{tabular}

$a$ : values expressed as $\log _{10} \mathrm{pfu} / \mathrm{ml} ; b$ : values expressed as $\log _{10} \mathrm{HLU} / \mathrm{ml}$; HL - hemolysis; HLU - hemolysis units.

The vaccine strains Schwarz and CAM-70 showed highly efficient replication in Vero cells and in CEF. All the clones replicated efficiently in Vero cells. In CEF, only clones 2 and 3 showed efficient replication; clone 1 showed intermediate replication efficiency and clone 4 showed no apparent replication (Fig. 3).

\section{DISCUSSION}

The Edmonston strain from which the clones were derived was passaged 70 times in tissue culture since its isolation. MRC-5, a human diploid cell line, was the last cell type in which it was passaged before coming to our hands, and no passages in chick cells were performed. Both vaccine strains, Schwarz and CAM-70 were attenuated through 163 and 147 passages, respectively, most of them in chick cells. The first licensed attenuated measles vaccine, Edmonston B, was derived from the Edmonston strain by additional passages in chick embryos and chick cells. The administration of this vaccine was associated with symptoms of the disease such as rash and high fever (Markowitz \& Katz 1994). Since the Edmonston virus used in the present study had not been passaged in chick embryo cells, it is highly likely to be more virulent than the Edmonston B strain, but considering the number of passages, it may no longer truly represent the original isolate.

Differences in the plaque size produced by strains of measles virus have been documented. In addition, some strains show multiple plaque sizes. No biological role directly related to plaque sizes has yet been assigned (Buynak et al. 1962, Rapp 1964, De Maeyer \& Enders 1965, Schumacher et al. 1972, Gould 1974, Mann et al. 1980). In some virus-cell systems, plaque size may be inversely related to multiplicity of infection due to the interferon system (De Mayer \& Enders 1965). Since Vero cells are defective in interferon production we did not observe any decrease in plaque size by increasing the infectious dose of the inoculum. Our results suggest that the intermediate plaques are less stable than the large and small plaques. The presence among the clones of plaques with the phenotype of the vaccine strains does not necessarily indicate that these viruses are attenuated.

Salt-dependent hemagglutination was first demonstrated by Schluederberg and Nakamura (1967). Measles virus isolates showing low hemagglutination activity or salt-dependent hemagglutination have been described (Shirodaria et al. 1976, Saito et al. 1992, Shibahara et al. 1994). Salt-dependence of the Schwarz strain, as well as the isotonic hemagglutination of the Edmonston-Zagreb (Ikic et al. 1972) vaccine strain was previously demonstrated (Shirodaria et al. 1976, Allison 1985). In our study we found the Schwarz and CAM-70 vaccine strains to be salt-dependent while all of the clones also hemagglutinated under isotonic conditions. The relationship between infectivity and hemagglutination titres showed quantitative differences between the clones. The difference between the vaccine strains and the clones and between clones under isotonic and hypertonic conditions was striking. The demonstration of hemagglutination and salt-dependent agglutination in non-attenuated strains as well as in vaccine strains indicates that the type of hemagglutination cannot be considered as an exclusive attenuation marker. 

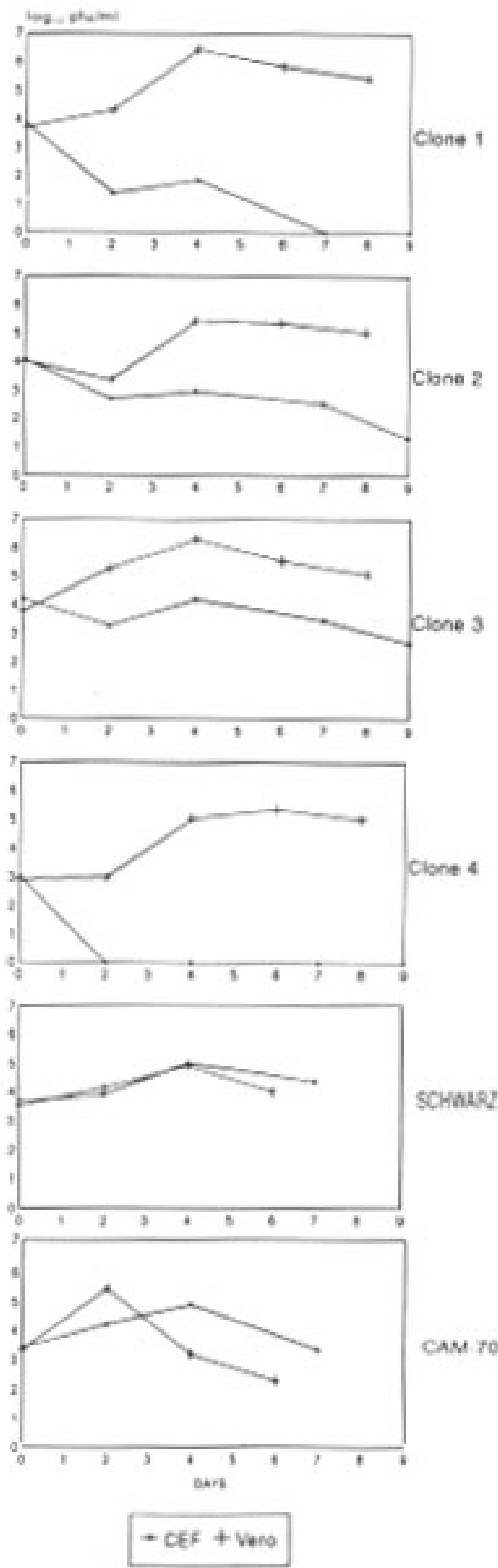

Fig. 3: viral replication in chick embryo fibroblasts and Vero cells. Relationship between infectious titre and days post-infection.
Hemolysis mediated by the measles virus fusion protein requires the participation of the hemagglutinin (Wild et al. 1991, Malvoisin \& Wild 1993). The vaccine strains Schwarz and CAM-70 did not produce hemolysis even in hypertonic conditions. The relationship between infectious and hemolytic titres may prove useful for the evaluation of quantitative differences between viruses. Hemolysis by a strain of measles virus having a salt-dependent hemagglutination has been described (Breschkin et al. 1977). On the other hand, the presence of hemagglutinin and absence of hemolysis has also been demonstrated (Norrby \& Falksveden 1964, Haspel et al. 1975). Fifty percent hemolysis were obtained in dilutions $10^{-3.3}$ for clone $1,10^{-2.4}$ for clone 2, $10^{-1.6}$ for clone 3 and $10^{-2.16}$ for clone 4. Allison (1985), using the Edmonston-Zagreb strain, obtained 50\% hemolysis with dilution $10^{-0.2}$. Sinitsyna et al. (1990), have suggested that the decrease in immunogenicity of overattenuated vaccines is related to a reduction in the expression of the fusion protein. It is possible, therefore, that a high number of passages and a corresponding reduction in the expression of the $\mathrm{F}$ protein might be reflected in the decrease or absence of hemolytic activity. Despite the apparent lower hemolytic activity of the Edmonston-Zagreb strain in relation to the clones, it was nevertheless demonstrable. This result is relevant since the Emonston-Zagreb strain was attenuated by 108 passages, and only $20 \%$ of those were performed in chick cells. These observations strengthen the hypothesis that the number of passages, particularly in CEF, affects the expression of the F protein.

Non-egg adapted viral strains replicate poorly or not at all in chick cells (Buynak et al. 1962). Similarly, the propagation in chick embryo fibroblasts was selected as the only marker which could distinguish vaccine from virulent strains (Schumacher et al. 1972). It is not clear whether the adaptation of the virus to chick cells is mediated by the presence of variants in the virus population which are selected through an alternative attachment and penetration pathway or if it is mediated by mutations accumulated during viral passages (Dörig et al. 1993, Dunster et al. 1995). Since RNA virus genomes show high mutation frequencies, the adaptation to specific host cells can possibly be related to nucleotide changes in the RNA molecules (Holland et al. 1982). For measles virus the molecular biological changes underlying this process remain unclear.

Our results confirm the ability of the Schwarz and CAM-70 vaccine strains to propagate in CEF, and a similar ability was observed in Vero cells. All the clones showed efficient replication in Vero 
cells. Based on the titres obtained for the clones grown in CEF, clones 2 and 3 showed efficient replication since both had detectable titres on day 9 p.i. Clone 1 showed intermediate replication efficiency with lower titres persisting to day 4 and no detectable virus on day 7 . Clone 4 showed no replication with results compatible with virus inactivation. Two of the clones showed characteristics similar to vaccine strains: clone 2 in terms of size and homogeneity of plaques, clone 3 in terms of hemolytic activity and both for the efficiency of propagation in CEF.

In our study the fact that all the plaque isolates do not completely share the biological features of the vaccine viruses can suggest that, if present, the attenuated phenotype was represented only in a very small proportion of the population and could not be selected by plaque picks. Also, repeated passages which were not performed in the Edmonston samples, could have favored mutations responsible for attenuation.

While none of the biological variations of measles strains have yet been explained on the basis of nucleotide sequence changes, further studies on the adaptation to chick cells and comparative genome sequencing can lead us to the identification of those sequences responsible for attenuation and contribute for the improvement of current vaccines.

\section{ACKNOWLEDGEMENTS}

To Dr Jussara P Nascimento for suggestions and comments; to Heloísa H Lopes dos Santos and Luiz Fernando C de Almeida for technical assistance. To Alfredo Jabor and Mauro França for help with computer work.

\section{REFERENCES}

Allison LMC 1985. Stability of measles virus in liquid suspensions. Thesis submitted to the University of London for the degree of Doctor of Philosophy, 246 pp.

Bellini WJ, Rota JS, Rota PA 1994. Virology of measles virus. J Infect Dis 170: 15-23.

Breschkin AM, Walmer B, Rapp F 1977. Hemagglutination variant of measles virus. Virology 80: 441444.

Buynak EB, Peck HM, Creamer AA, Goldner H, Hilleman MR 1962. Differentiation of virulent from avirulent measles strains. Amer J Dis Child 103: 460-473.

De Maeyer E, Enders JF 1965. Growth characteristics, interferon production and plaque formation with different lines of Edmonston measles virus. Arch ges Virusforsch 16: 151-160.

Dörig RE, Marcil A, Chopra A, Richardson CD 1993. The human CD46 molecule is a receptor for measles virus (Edmonston strain). Cell 75: 295-305.

Dulbecco R, Vogt M 1954. Plaque formation and isolation of pure lines with poliomyelitis viruses. $J$ Exp Med 99: 167-182.
Dunster LM, Schneider-Schaulies J, Dehoff MH, Holers VM, Schwartz-Albiez R, ter Meulen V 1995. Moesin, and not the murine functional homologue (Crry/p65) of human membrane cofactor protein (CD46), is involved in the entry of measles virus (strain Edmonston) into susceptible murine cell lines. J Gen Virol 76: 2085-2089.

Gellin B, Katz S 1994. Measles: state of the art and future directions. J Infect Dis 170: 3-14.

Gould E 1974. Variants of measles virus. Med Microbiol Immunol 160: 211-219.

Haspel MV, Duff R, Rapp F 1975. Isolation and preliminary characterization of temperature-sensitive mutants of measles virus. J Virol 16: 1000-1009.

Holland J, Spindler K, Horodyski F, Grabau E, Nichol S, VandePol S 1982. Rapid evolution of RNA genomes. Science 215: 1577-1585.

Hu A, Sheshberadaran H, Norrby E, Kövamees J 1993. Molecular characterization of epitopes on the measles virus hemagglutinin protein. Virology 192 : 351-354.

Hummel KB, Erdman DD, Heath J, Bellini WJ 1992. Baculovirus expression of the nucleoprotein gene of measles virus and utility of the recombinant protein in diagnostic enzyme immunoassays. J Clin Microb 30: 2874-2880.

Ikic D, Juzasic M, Beck M, Hrabar A, Cimbur-Schreiber $\mathrm{T}$ 1972. Attenuation and characterization of Edmonston-Zagreb measles virus. Ann Immunol Hung 16: 175-181.

Malvoisin E, Wild TF 1993. Measles virus glycoproteins: studies on the structure and interaction of the haemagglutinin and fusion proteins. J Gen Virol 74: 2365-2372.

Mann GF, Allison LMC, Agostini CFM, Zuckerman AJ 1980. A simplified plaque assay system for measles virus. J Biol Stand 8: 219-225.

Markowitz LE, Katz SL 1994. Measles vaccine, p. 229276. In SA Plotkin, EA Mortimer (eds) Vaccines. Philadelphia.

McKimm J, Rapp F 1977. Variation in the ability of measles virus progeny to induce interferon. Proc Natl Acad Sci 74: 3056-3059.

Norrby ECJ, Falksveden LG 1964. Some general properties of the measles virus hemolysin. Arch ges Virusforsch 14: 474-486.

Rapp F 1964. Plaque differentiation and replication of virulent and attenuated strains of measles virus. $J$ Bact 88: 1448-1458.

Rhim JS, Schell K, Creasy B 1969. Biological characteristics and viral susceptibility of an African green monkey kidney cell line (Vero). Proc Soc Exp Biol Med 132: 670-678.

Rota JS, Wang ZD, Rota P, Bellini WJ 1994. Comparison of sequences of the $\mathrm{H}, \mathrm{F}$, and $\mathrm{N}$ coding genes of measles virus vaccine strains. Virus Res 31: $317-$ 330.

Rubin H 1973. Chick embryo cells, p. 119-123. In PF Kruse, MK Patterson (eds) Tissue culture methods and application. London.

Saito H, Sato H, Abe M, Harata S, Amano K, Suto T, Morita M 1992. Isolation and characterization of the 
measles virus strains with low hemagglutination activity. Intervirology 33: 57-60.

Schluederberg A, Nakamura N 1967. A salt-dependent hemagglutinating particle from measles-infected cells. Virology 33: 297-306.

Schumacher HP, Albrecht P, Tauraso NM 1972. Markers for measles virus. Tissue culture properties. Archiv Virol 36: 296-310.

Shibahara K, Hotta H, Katayama Y, Homma M 1994. Increased binding activity of measles virus to monkey red blood cells after long-term passage in Vero cell cultures. J Gen Virol 75: 3511-3516.
Shirodaria PV, Dermott E, Gould EA 1976. Some characteristics of salt-dependent haemagglutinating measles viruses. J Gen Virol 33: 107-115.

Sinitsyna OA, Khudaverdyan OE, Steinberg LL, Nagieva FG, Lotte VD, Dorofeeva LV, Rozina EE, Boriskin YS 1990. Further-attenuated measles vaccine: virus passages affect viral surface protein expression, immunogenicity and histopathology pattern in vivo. Res Virol 141: 517-531.

Wild TF, Malvoisin E, Buckland R 1991. Measles virus: both the haemagglutinin and fusion protein are required for fusion. J Gen Virol 72: 439-442. 
514 Biological Characterization of Measles Virus Strains - MBJ Borges et al. 